Research Paper

\title{
AB0 Blood Group and Ovarian Cancer Survival
}

\author{
Vincenzo Dario Mandato ${ }^{* \bowtie}$, Federica Torricelli2 ${ }^{*}$, Valentina Mastrofilippo ${ }^{3}$, Gino Ciarlini ${ }^{3}$, Debora Pirillo ${ }^{1}$, \\ Gianluca Annunziata ${ }^{1}$, Bruno Casali ${ }^{4}$, Martino Abrate ${ }^{3}$, Giovanni Battista La Sala ${ }^{1}$, Lorenzo Aguzzoli ${ }^{3}$ \\ 1. Unit of Obstetrics and Gynaecology, Azienda Unità Sanitaria Locale - IRCCS, Reggio Emilia, Italy; \\ 2. Laboratory of Translational Research, Azienda Unità Sanitaria Locale - IRCCS, Reggio Emilia, Italy; \\ 3. Unit of Surgical Gynecol Oncology, Azienda Unità Sanitaria Locale - IRCCS, Reggio Emilia, Italy; \\ 4. Laboratory of Molecular Biology, Azienda Unità Sanitaria Locale - IRCCS, Reggio Emilia, Italy. \\ * These two authors contributed equally \\ $\square$ Corresponding author: Vincenzo Dario Mandato, PhD, Unit of Obstetrics and Gynecology, Azienda Unità Sanitaria Locale -IRCCS, Reggio Emilia. Viale \\ Risorgimento 80, 42123 Reggio Emilia (Italy). Tel: +39 3494640813, Fax: +39 0522296015, e-mail: dariomandato@gmail.com \\ (c) Ivyspring International Publisher. This is an open access article distributed under the terms of the Creative Commons Attribution (CC BY-NC) license \\ (https://creativecommons.org/licenses/by-nc/4.0/). See http://ivyspring.com/terms for full terms and conditions.
}

Received: 2018.08.16; Accepted: 2019.01.16; Published: 2019.04.25

\begin{abstract}
Background: Epithelial ovarian cancer is the most lethal gynecological malignancy because is usually diagnosed at advanced stage. New prognostic factors have been investigated but these biomarkers do not have a strong direct relationship with survival. Several studies investigated the association between $A B O$ blood group with ovarian cancer but with conflicting results. We investigated the association between $A B O$ blood group and epithelial ovarian cancer patients consecutively surgically treated at our department from 2004 to 2015.

Methods: Clinical charts of ovarian cancer patients treated and followed from 2004 to 2015 were checked for inclusion and exclusion criteria. Clinical and pathological data were recorded in an electronic separate, anonymous, password-protected database. All relevant data were extrapolated and used for final analysis.

Results: A population of 265 ovarian cancer patients was analyzed in this study. 121 (45.6\%) patients presented blood type 0, $112(42.3 \%)$ had blood type A, 23 (8.7\%) B and 9 (3.4\%) AB. A significantly lower percentage of death (8.7\%) in patients with blood type $B$ in comparison with patients presenting different genotypes (group 0: $34.7 \%$, group A: $32.1 \%$, group AB: $22.2 \%$ ) was found. In invasive serous ovarian cancer patients the analysis showed a 5 fold significant reduction of the risk of death in patients with $B$ genotype. However, postoperative residual tumor resulted the most important prognostic factor for overall survival.

Conclusions: $A B 0$ blood group might be a preoperative prognostic factor in epithelial ovarian cancer patients. According to the literature, postoperative residual disease remain the most important prognostic factor also in our study.
\end{abstract}

Key words: ovarian cancer, AB0 blood group, survival, prognostic factor, residual disease, neoadjuvant therapy

\section{Introduction}

Epithelial ovarian cancer (EOC) is the most lethal gynecological malignancy, 238,700 new cancer cases and 151,900 cancer deaths worldwide were recorded in the 2012 [1]. EOC represents the eighth cause of death for tumor in the women worldwide [1]. In the 2016, the Italian Association of Cancer Registries reported 5,200 new cancer cases and 3,302 cancer deaths [2]. Five years overall survival (OS) is of $45 \%$ [3] because EOC is usually diagnosed at advanced stage and no specific symptoms or diagnostic tools are available for early diagnosis [3,4]. When EOC is limited to the ovary (stages IA and IB), 5 years OS raise to $92 \%$. However, only $15 \%$ of all EOC are found at this early stage [3] therefore EOC diagnosis is usually characterized by severe physical and psychological sequelae [5]. Border line ovarian tumors (BOT) are less aggressive of EOC and affect women younger than those affected by EOC. Usually, BOT 
require only a surgical therapy and are characterized by a good prognosis.

Well know prognostic factors are age, obesity, performance status, histology, stage, grade, centralization and residual disease after surgery $[6,7]$.

Several new prognostic factors in EOC have been investigated such as tumor suppressor protein 53 (p53), oncogenes epidermal growth factor receptor (EGFR), human epidermal growth factor receptor 2 (HER-2/neu), B-cell lymphoma 2 (Bcl-2), haptoglobin, but results of a recent meta-analysis showed that these biomarkers do not have a strong direct relationship with survival, although likely their respective pathways do influence patients prognosis $[6,8,9]$.

Since the first link between AB0 blood type and cancer was described in 1953, numerous studies investigated the association between $\mathrm{AB} 0$ blood group with gynecological [10] and non-gynecological cancers $[11,12]$.

Recently, meta-analysis confirmed that non-0 blood types are associated with significantly increased risk of gastric and pancreatic cancer [12-15], on contrary, for the other malignancies, data are inconsistent [13].

Since fifties, also the interaction between $\mathrm{AB} 0$ blood group and EOC has been investigated by several studies [16-31] but frequently conflicting results have been published (Table 1 ).

Here, we investigated the association between AB0 blood group with both BOT and EOC in the patients consecutively surgically treated at our department from 2004 to 2015.

Table 1. ABO blood groups and epithelial ovarian cancers: results reported in literature.

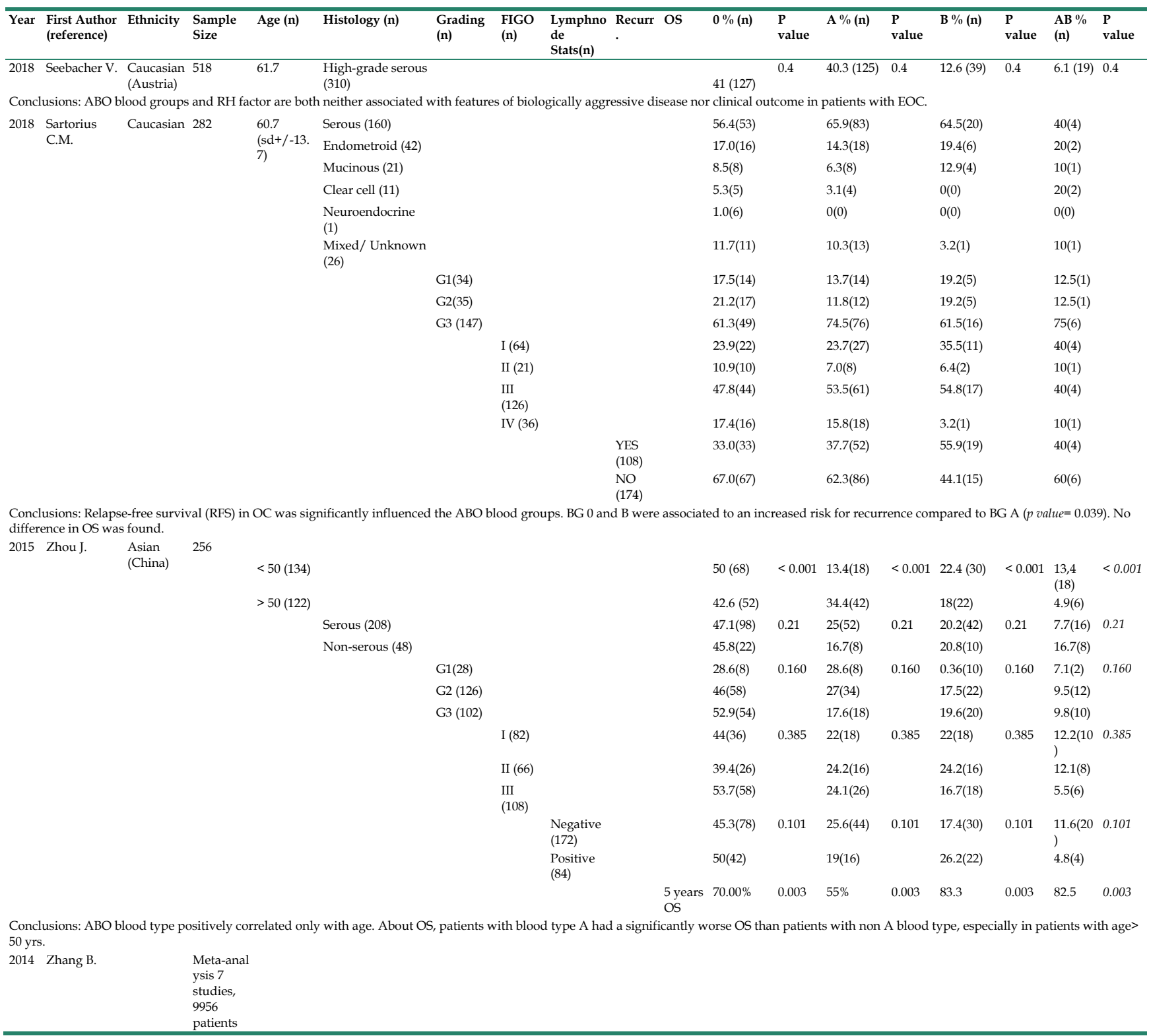


tumor, inadequate EOC management according to internal and international guidelines [33-35], an age less than 18 years, non-Caucasian ancestry, a follow-up length less than of 6 months, inadequate follow-up according to internal guidelines, absence of written informed consent, diagnosis of a previous or concurrent cancer(s) and unavailable follow-up data.

An "adequate" management was considered as follows: in apparent early stage BOT a total extrafascial hysterectomy (TEH) with bilateral salpingooophorectomy (BSO) infracolonic omentectomy, multiple peritoneal biopsy and peritoneal washing was the standard staging procedure; appendectomy was performed in case of mucinous histotype; whereas additional procedures such as radical omentectomy, pelvic and paraaortic lymph node dissection were performed in case of early stage EOC. In case of BOT with multiple implants or advanced EOC a debulking surgery with excision of all macroscopic disease was performed. In these cases additional procedures such as bowel resection, spelenectomy, liver resection, diaframmectomy, peritonectomy were performed. Adjuvant chemotherapy should be administered to early stage suboptimally staged patients and to those at early stage optimally staged patients at higher risk of recurrence such as stage $1 B / C$ grade $2 / 3$, any grade 3 or clear-cell histology [33-35]. Moreover, chemotherapy is recommended for all patients with FIGO stage II-IV disease post-surgery. Standard chemotherapy consists of a combination of paclitaxel $175 \mathrm{mg} / \mathrm{m} 2$ and carboplatin AUC 6-5, both administered intravenously every three weeks for six months [34,35]. Since 2013 anti-angiogenic therapy was added to the standard therapy for FIGO stage IIIb-IV. Bevacizumab was offered at $7.5 \mathrm{mg} / \mathrm{kg}$ IV repeated every three weeks for six cycles and continued for up to 12 additional cycles $[34,35]$. Women affected by severe comorbidity or unresectable disease at upfront surgery were submitted to neoadjuvant chemotherapy. Neoadjuvant chemotherapy consisted of $3 / 4$ cycles of combination of paclitaxel and carboplatin. A followup was defined "adequate" in case of adherence to the following schedule: physical and gynecological examination, and transvaginal ultrasound every 12 months, CA 125 evaluation and chest/abdominal/ pelvic computed tomography scan every 6 months for 5 years.

Further investigations such as chest X-ray, positron emission tomography scan were performed if clinically indicated.

The same pathologists with long-time expertise in gynecological oncology reviewed all the histological samples in order to confirm formally the diagnosis.

\section{Statistical analysis}

For statistical analysis $\mathrm{R}$ statistical software package version 3.1.1 ( $R$ foundation for Statistical Computing, Vienna, Austria) was used.

Univariate associations between $\mathrm{AB} 0$ genotypes and clinic-pathological variables were assessed by Fisher's exact test and generalized linear models.

The overall survival (OS) was calculated as the period spent from the date of surgery to the date of death or last follow up. Analyses of overall survival between $\mathrm{AB} 0$ blood groups were performed applying Cox regression hazard model and Hazard ratio (HR) values were calculated. Kaplan Meier curves were used to represent overall survival trends in different groups of patients.

Significant statements referred $\mathrm{P}$ values lower than 0.05 .

\section{Results}

\section{Patient characteristics}

A population of 265 patients with BOT and EOC selected for inclusion and exclusion criteria was analyzed in this study. One hundred and twenty one (45.6\%) patients presented blood type 0, $112(42.3 \%)$ had blood type A, 23 (8.7\%) B and 9 (3.4\%) AB. Blood groups frequencies overlapped with those described for total Italian population (0: $46 \%$, A: $42 \%$, B: $9 \%$, AB: $3 \%)$.

In table 2 the distribution of $\mathrm{AB} 0$ groups was investigate in association with principal clinical and pathological characteristics of patients. Interestingly we observed a significantly lower percentage of death $(8.7 \%)(p=0.024)$ in patients with blood type B in comparison with patients presenting different genotypes (group 0: $34.7 \%$, group A: $32.1 \%$, group AB: $22.2 \%)$.

\section{ABO blood groups and invasive ovarian cancer}

To better investigate the relation between $B$ group and risk of death in ovarian cancer patients we excluded BOT and performed an OS analysis focusing on 224 EOC and subsequently on a subgroup of 176 more aggressive serous invasive tumors because no significant correlation was found with histotypes other than serous (data not shown). In all EOC and particularly in serous EOC the analysis confirmed the protective role of $\mathrm{B}$ genotype in EOC risk, showing about a 5 fold significant reduction of the risk of death (Table 3, Fig. 1).

Further analyses were focused on the serous invasive tumors and a univariate and multivariate survival analysis including the principal clinical and pathological characteristics of these patients were included. (Table 4). As expected, in univariate 
analysis, in addition to blood group, age, neoadjuvant therapy and presence of residual tumor after surgery resulted the principal parameters influencing OS of serous EOC patients.

A bootstrap approach $(b=1000)$ was used to perform an internal validation of the univariate association between AB0 group and OS. Analysis conducted on total population $(\mathrm{p}=0.022)$, EOC $(\mathrm{p}=$ 0.049 ) and serous invasive EOC (0.084) confirmed the significant effect of blood groups on the risk of death.

Because the evident effect of the presence of residual tumor (RT) on patients survival two different model of multivariate analysis were considered. In model 1 postoperative RT and neoadjuvant therapy were excluded from the analysis and a significant, independent effect of blood group $B$ (Hazard ratio $(\mathrm{HR})=0.20, \mathrm{P}$ adjusted $=0.041)$ and age $(\mathrm{HR}=1.04, \mathrm{P}$ adjusted $=0.015$ ) on the risk of death in serous EOC was confirmed. In model 2 of multivariate analysis the presence of postoperative RT resulted the most important prognostic factor for OS $(\mathrm{HR}=3.54, \mathrm{P}$ adjusted $=0.004$ ) and both blood group and neoadjuvant therapy loss their significant effect.

Table 2. Analysis of association between blood groups and clinical and pathological characteristics of patients with BOT and EOC.

\begin{tabular}{|c|c|c|c|c|c|c|c|c|c|}
\hline & \multirow{3}{*}{ Tot $(100 \%)$} & \multicolumn{8}{|c|}{ Blood Groups } \\
\hline & & \multicolumn{2}{|c|}{0} & \multicolumn{2}{|l|}{ A } & \multicolumn{2}{|l|}{ B } & \multicolumn{2}{|l|}{ AB } \\
\hline & & n (\%) & P value & n (\%) & Pvalue & n (\%) & P value & n (\%) & Pvalue \\
\hline & 265 & 121 & & 112 & & 23 & & 9 & \\
\hline \multicolumn{10}{|l|}{ Age } \\
\hline$\leq 61$ & $133(50.1)$ & $59(48.8)$ & - & $56(50.0)$ & 0.850 & $13(56.5)$ & 0.496 & $5(55.6)$ & 0.695 \\
\hline$>61$ & $132(49.9)$ & $62(51.2)$ & & $56(50.0)$ & & $10(43.5)$ & & $4(44.4)$ & \\
\hline \multicolumn{10}{|l|}{ Ipertension } \\
\hline No & $143(57.7)$ & $63(54.8)$ & - & $64(60.4)$ & 0.401 & $11(55.0)$ & 0.986 & $5(71.4)$ & 0398 \\
\hline Yes & 105 (42.3) & $52(45.2)$ & & $42(39.6)$ & & $9(45.0)$ & & $2(28.6)$ & \\
\hline$N A$ & 17 & 6 & & 6 & & 3 & & 2 & \\
\hline \multicolumn{10}{|l|}{ Diabetes } \\
\hline No & $226(93.0)$ & 102 (91.9) & - & 99 (93.4) & 0.672 & 18 (94.7) & 0.670 & $7(100.0)$ & 0.992 \\
\hline Yes & $17(7.0)$ & $9(8.1)$ & & $7(6.6)$ & & $1(5.3)$ & & $0(0.0)$ & \\
\hline$N A$ & 22 & 10 & & 6 & & 4 & & 2 & \\
\hline \multicolumn{10}{|l|}{ FIGO_stage } \\
\hline$I-I I$ & $69(30.3)$ & 33 (32.3) & - & $27(27.3)$ & 0.405 & $7(36.8)$ & 0.723 & $2(22.2)$ & 0.523 \\
\hline$I I I-I V$ & $159(69.7)$ & $68(67.3)$ & & $72(72.7)$ & & $12(63.2)$ & & $7(77.8)$ & \\
\hline$N A$ & 37 & 20 & & 13 & & 4 & & 0 & \\
\hline \multicolumn{10}{|l|}{ Grade } \\
\hline G1 & 29 (12.9) & 13 (13.3) & - & $13(13.1)$ & 0.978 & $2(9.5)$ & 0.641 & 1 (14.3) & 0.939 \\
\hline G2 & $17(7.5)$ & $5(5.1)$ & & 11 (11.1) & & $1(4.8)$ & & $0(0.0)$ & \\
\hline G3 & $179(79.6)$ & $80(81.6)$ & & $75(75.8)$ & & $18(85.7)$ & & $6(85.7)$ & \\
\hline$N A$ & 40 & 23 & & 13 & & 2 & & 2 & \\
\hline \multicolumn{10}{|c|}{ Postoperative residual tumor } \\
\hline No & $183(87.6)$ & $83(86.5)$ & - & $76(87.4)$ & 0.978 & $16(88.9)$ & 0.641 & $8(100.0)$ & 0.939 \\
\hline Yes & $26(12.4)$ & $13(13.5)$ & & $11(12.6)$ & & $2(11.1)$ & & $0(0.0)$ & \\
\hline NA & 56 & 25 & & 25 & & 5 & & 1 & \\
\hline $\begin{array}{l}\text { Neoadjuvant treatment } \\
\text { in EOC }\end{array}$ & 224 & 100 & & 95 & & 21 & & 8 & \\
\hline No & $160(76.2)$ & $75(78.1)$ & - & $65(74.7)$ & 0.587 & $14(73.7)$ & 0.673 & $6(75.0)$ & 0.838 \\
\hline Yes & $50(23.8)$ & $21(21.9)$ & & $22(25.3)$ & & $5(26.3)$ & & $2(25.0)$ & \\
\hline$N A$ & 14 & 4 & & 8 & & 2 & & 0 & \\
\hline \multicolumn{10}{|l|}{ Invasiveness } \\
\hline Borderline & $40(15.2)$ & $20(16.7)$ & - & $17(15.2)$ & 0.757 & $2(8.7)$ & 0.341 & $1(11.1)$ & 0.666 \\
\hline Invasive & $224(84.8)$ & $100(83.3)$ & & $95(84.8)$ & & $21(91.3)$ & & $8(88.9)$ & \\
\hline$N A$ & 1 & 1 & & 0 & & 0 & & 0 & \\
\hline \multicolumn{10}{|l|}{ Histology } \\
\hline Serous & $191(72.3)$ & $82(68.3)$ & - & $83(74.1)$ & 0.333 & $19(82.6)$ & 0.177 & $7(77.8)$ & 0.558 \\
\hline Not serous & $73(27.7)$ & $38(31.7)$ & & $29(25.9)$ & & $4(17.4)$ & & $2(22.2)$ & \\
\hline$N A$ & 1 & 1 & & 0 & & 0 & & 0 & \\
\hline \multicolumn{10}{|l|}{ Death } \\
\hline No & $183(69.1)$ & $79(65.3)$ & - & $76(67.9)$ & 0.678 & $21(91.3)$ & 0.024 & $7(77.8)$ & 0.451 \\
\hline Yes & $82(30.9)$ & $42(34.7)$ & & $36(32.1)$ & & $2(8.7)$ & & $2(22.2)$ & \\
\hline \multicolumn{10}{|l|}{ Recurrence } \\
\hline No & $117(57.6)$ & $56(57.1)$ & - & $52(60.5)$ & 0.749 & $6(42.9)$ & 0.304 & $3(60.0)$ & 0.663 \\
\hline Yes & $86(42.2)$ & $42(42.9)$ & & $34(39.5)$ & & $8(57.1)$ & & $2(40.0)$ & \\
\hline Persistence of disease & 26 & 13 & & 11 & & 2 & & 0 & \\
\hline$N A$ & 36 & 10 & & 15 & & 7 & & 4 & \\
\hline
\end{tabular}


Table 3. Overall survival analysis in $B O T$ and $E O C$ patients with different $A B O$ groups.

\begin{tabular}{|c|c|c|c|c|c|}
\hline & Patients (n) & Events $(n, \%)$ & Median (months) & HR & Pvalue \\
\hline \multicolumn{6}{|c|}{ Total population (BOT+EOC) (265) } \\
\hline 0 & 121 & $42(34.7)$ & 61 & & \\
\hline A & 112 & $36(32.1)$ & 71 & 0.88 & 0.588 \\
\hline B & 23 & $2(8.7)$ & NA & 0.16 & 0.011 \\
\hline $\mathrm{AB}$ & 9 & $2(22.2)$ & NA & 0.66 & 0.572 \\
\hline \multicolumn{6}{|c|}{ EOC (224) } \\
\hline 0 & 100 & $39(39.0)$ & 57 & & \\
\hline A & 95 & $32(33.7)$ & 71 & 0.83 & 0.433 \\
\hline B & 21 & $2(9.5)$ & NA & 0.18 & 0.018 \\
\hline $\mathrm{AB}$ & 8 & $2(25.0)$ & NA & 0.74 & 0.677 \\
\hline \multicolumn{6}{|c|}{ Serous EOC (176) } \\
\hline 0 & 75 & 31 (41.3) & 51 & & \\
\hline A & 77 & $26(33.8)$ & 56 & 0.85 & 0.538 \\
\hline B & 18 & $2(11.1)$ & NA & 0.20 & 0.027 \\
\hline $\mathrm{AB}$ & 6 & $2(33.3)$ & 49 & 0.87 & 0.847 \\
\hline
\end{tabular}

The analysis was performed on total study population (BOT+EOC) and on patients with only EOC and only serous EOC.

Table 4. Univariate and multivariate analysis of survival in serous EOC. In multivariate analysis model 1 neoadjuvant therapy and presence of postoperative residual tumor were excluded, while they were considered in model 2.

\begin{tabular}{|c|c|c|c|c|c|c|}
\hline & \multicolumn{2}{|c|}{ Univariate Cox Model } & \multicolumn{2}{|c|}{ Multivariate Cox Model 1} & \multicolumn{2}{|c|}{ Multivariate Cox Model 2} \\
\hline & HR (C.I 95\%) & P value & HR (C.I 95\%) & P value & HR (C.I 95\%) & P value \\
\hline \multicolumn{7}{|l|}{ AB0 group } \\
\hline 0 & 1 & - & 1 & - & & \\
\hline$A$ & $0.85(0.50-1.43)$ & 0.537 & $0.82(0.44-1.55)$ & 0.544 & $0.81(0.37-1.75)$ & 0.587 \\
\hline$B$ & $0.20(0.05-0.83)$ & 0.027 & $0.20(0.04-0.93)$ & 0.041 & $0.32(0.07-1.51)$ & 0.149 \\
\hline$A B$ & $0.87(0.21-3.65)$ & 0.847 & $1.59(0.36-7.02)$ & 0.539 & $3.55(0.71-17.8)$ & 0.123 \\
\hline Age & $1.03(1.00-1.05)$ & 0.016 & $1.04(1.01-1.07)$ & 0.015 & $1.07(1.03-1.11)$ & 0.0003 \\
\hline Ipertension & $1.23(0.73-2.09)$ & 0.438 & $1.07(0.53-2.16)$ & 0.847 & $1.65(0.75-3.64)$ & 0.212 \\
\hline Diabetes & $1.31(0.47-3.64)$ & 0.606 & $1.20(0.26-5.52)$ & 0.814 & $1.21(0.24-6.00)$ & 0.820 \\
\hline \multicolumn{7}{|l|}{ FIGO stage } \\
\hline$I-I I$ & 1 & - & 1 & - & - & - \\
\hline III-IV & $2.19(0.68-7.02)$ & 0.188 & $1.63(0.50-5.33)$ & 0.418 & $1.50(0.19-11.9)$ & 0.702 \\
\hline \multicolumn{7}{|l|}{ Grade } \\
\hline G1-G2 & 1 & - & 1 & - & 1 & - \\
\hline G3 & $3.73(0.52-27.0)$ & 0.193 & $2.33(0.31-17.26)$ & 0.409 & $1.72(0.22-13.4)$ & 0.608 \\
\hline Postoperative residual tumor & $2.28(1.14-4.57)$ & 0.020 & - & - & $3.98(1.63-9.71)$ & 0.002 \\
\hline Neoadjuvant treatment & $1.76(0.94-3.28)$ & 0.078 & - & - & $1.42(0.63-3.24)$ & 0.401 \\
\hline
\end{tabular}

\section{Discussion}

In this retrospective study, B blood type patients showed a better OS compared with non-B blood- type patients both in BOT and EOC patients (Fig.1a). This result was confirmed also in the group of only EOC patients (Fig.1b) and in the group of only serous EOC patients (Fig. 1c).

To date, 16 studies investigated the impact of AB0 blood-group on EOC with different results (Table 1) [16-31]. Most of these studies reported that A blood type was associated with an increased ovarian cancer risk, particularly in premenopausal women [22]. Moreover, A blood type was associated with worse OS [19,23], especially in patients over 50 years of age [19]. A recent meta-analysis including 9956 EOC patients coming from 7 studies, confirmed that A blood type was associated with increased EOC risk, on contrary 0 blood type was associated with decreased EOC risk [19, 25]. Poole in a genotyping study on 5232 EOC patients showed a modestly increased EOC risk particularly in A0 but not AA diplotype [17]. Differently by previous studies, Gates reported that $B$ antigen was positively associated with an increased incidence of EOC and A antigen was not [21]. Moreover, in a Chinese cohort study, B blood group was associated with a reduced risk of genitourinary cancer in male [36].

How AB0 antigens may influence EOC prognosis is not well established. AB0 antigens are expressed on many cell types including platelets, vascular endothelial cells, epithelial tissues, mucus secretions [12] and tumor cells. Moreover, A antigen can be detected also in tumor cells from non-A individuals. A dysregulation of the enzymatic activity of the AB0 glycosyltransferases, can lead to conformational changes in proteins, such as the epidermal growth factor receptor or alter immune recognition of natural killer cells which are specifically involved in the processes of intercellular adhesion and cellular membrane signaling as well as in the immune response to the host [37-39]. These are all conditions that favor tumorigenesis [40]. 
Recently, studies reported an association between polymorphisms at the $\mathrm{AB} 0$ gene locus and circulating levels of tumour necrosis factor-alpha, soluble intercellular adhesion molecule (ICAM)-1 [41]. ICAM-1 is used by cancer cells for adhesion to endothelial cells and subsequent metastatisation [42], the decreased soluble ICAM levels in patients with A blood group may promote metastatic spread of tumours [15].

The AB0 gene is located on chromosome 9q34 encodes glycosyltransferases, which is frequently lost in EOC $[43,44]$. The gene encodes for glycosyltransferases, which catalyze the step-by-step transfer of nucleotide donor sugars to the $\mathrm{H}$ antigen to form the $A$ and $B$ antigen [44]. Aberrant glycosylation represents a hallmark of cancer development and progression [45]. Thus, some authors hypothesized that patients with blood type A have impacted tumor cell invasion and immune responses of EOC cells and more susceptible to disease failure [18].

Moreover, AB0 blood group antigen expression on cancer cells is modified by hypermethylation of AB0 gene promoter [46], which might be related with

A. Total Population (BOT+EOC)
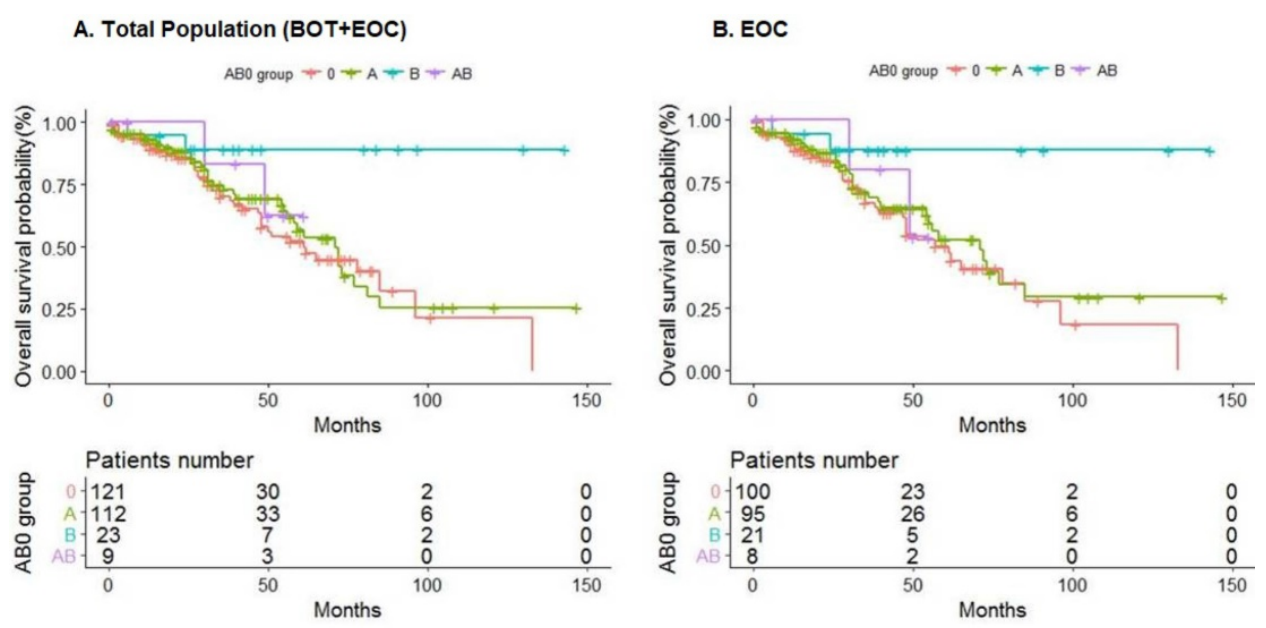

C. Serous EOC

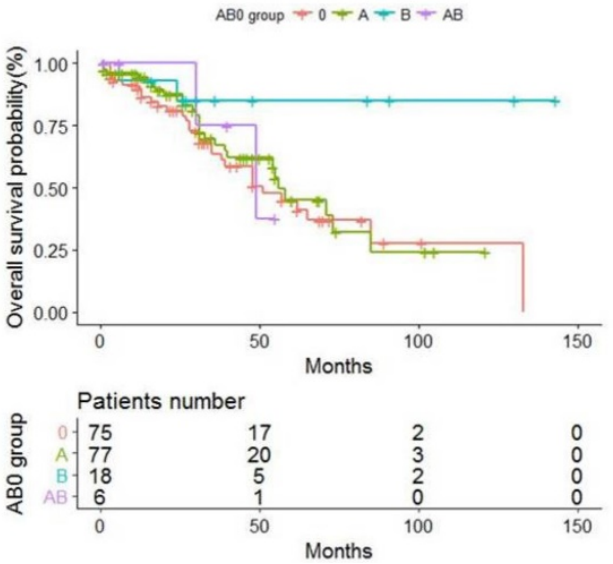

Figure 1. Kaplan Meier curves representing overall survival trend in different AB0 groups: (a) Total population (BOT+EOC) in study; (b) EOC; (c) Serous EOC. Risk tables refer to the number of patients at risk at each time point.

the tumor invasion and metastasis. The number of methylated gene promoters increased with age [47, 48], which may partly explain the reason for patients with age $>50$ years had worse OS [18].

Age is a well know prognostic factor in EOC patients, in our study at univariate analysis age, AB0 blood group, FIGO stage, neoadjuvant therapy, invasiveness and postoperative RT resulted to affect OS, but at multivariate analysis only age, FIGO stage and postoperative RT resulted to affect OS whilst AB0 blood group continued to affect OS only if postoperative RT was not included in multivariate analysis. So we may hypothesize that $\mathrm{AB} 0$ blood group might be a preoperative prognostic factor of EOC patients. According to the literature, postoperative residual disease remains the most important prognostic factor also in our study (HR 2.82).

In a previous study [18] on 256 EOC patients, blood group antigen A was associated with a significantly worse OS at multivariate analysis, but only patients without RT were analyzed. 
Our findings confirm data coming from a recent multi-centre study [31] in which blood group antigen $B$ was associated with a prolonged survival in patients with serous or undifferentiated EOC but this effect was not independent from standard prognostic parameters in multivariate analysis [31]. Differently from the latest studies $[18,31]$, we investigated also BOT in the total population (Fig.1a).

Most previous studies have potential flaws [17], relied on self-reported blood group [18], showed a tendency to over-report the less common blood groups [15], had lack of adjustment for potential confounders, such as age and race and postoperative RT $[18,21]$.

In our study we included only patients with blood group assessed at our hospital, AB0 frequencies were comparable to the common population, oncologic outcome were similar to that reported in literature, we tested the impact of $\mathrm{AB} 0$ blood group for all well know prognostic factors such as age and postoperative residual tumor. A single-centre study guarantees uniformity in surgical/medical treatment, pathological evaluation and management of patients. On contrary, the main limitation of the present study is the small sample size.

Considering the wide distribution of $\mathrm{AB} 0$ antigens on several cells and secretion and the several cellular functions based on AB0 antigens, it is unlike to exclude a function of $\mathrm{AB} 0$ in cancer risk and development. Despite several plausible mechanisms are reported to justify the link between $\mathrm{AB} 0$ and cancer, only gastric and pancreatic cancer showed a clear link [12, 15], on contrary EOC is still under investigation. A blood group is the most reported to be associated with EOC risk and poor OS, B blood group seems to be associated with a better OS in our study. AB0 blood group is present in all population, is easy and cheap to test and might represent a useful prognostic factor to use in the preoperative evaluation. Largest cooperative study should be planned to obtain a likely answer.

\section{Abbreviations}

EOC, epithelial ovarian cancer; BOT, border line ovarian tumor; OS, overall survival; P53, protein 53 EGFR, oncogenes epidermal growth factor receptor; HER-2/neu, human epidermal growth factor receptor 2; Bcl-2, B-cell lymphoma 2; RT, residual tumor; HR, hazard ratio; ICAM, soluble intercellular adhesion molecule; STROBE, Strengthening the Reporting of Observational Studies in Epidemiology; TEH, total extrafascial hysterectomy; BSO, bilateral salpingooophorectomy.

\section{Author Contributions}

All authors have made substantial contributions to the conception and design of the study. V.D.M. performed operations, conceived and designed the study and wrote the manuscript. F.T. performed statistical analysis, analyzed the data and wrote the manuscript. V.M. recruited patients, collected data and revised the literature. G.C. D.P., G.A., M.A. and L.A. performed operations and follow up. B.C. conceived the manuscript. G.B.L. wrote the manuscript.

\section{Competing Interests}

The authors have declared that no competing interest exists.

\section{References}

1. Torre LA, Bray F, Siegel RL, Ferlay J, Lortet-Tieulent J, Jemal A. Global cancer statistics, 2012. CA Cancer J Clin. 2015; 65:87-108.

2. Mangone L. Pinto C. I numeri del cancro in Italia. Reggio Emilia, Italy. 2016

3. American Joint Committee on Cancer. Ovary and Primary Peritoneal Carcinoma . In: AJCC Cancer Staging Manual. 7th ed. New York: Springer; 2010: 419-428.

4. Das PM, Bast RC Jr. Early detection of ovarian cancer. Biomark Med. 2008;2:291-303.

5. Mangone L, Mandato VD, Gandolfi R, Tromellini C, Abrate M. The impact of epithelial ovarian cancer diagnosis on women's life: a qualitative study. Eur J Gynaecol Oncol. 2014;35: 32-8.

6. Ezzati M, Abdullah A, Shariftabrizi A, Hou J, Kopf M, Stedman JK, Samuelson R, Shahabi S. Recent Advancements in Prognostic Factors of Epithelial Ovarian Carcinoma. Int Sch Res Notices. 2014;2014: 953509.

7. Mandato VD, Abrate M, De Iaco P, Pirillo D, Ciarlini G, Leoni M, Comerci G, Ventura A, Lenzi B, Amadori A, Rosati F, Martinello R, De Palma R, Ventura C, Belotti LM, Formisano D, La Sala GB; Gynecological Oncology Network of Emilia Romagna Region. Clinical governance network for clinical audit to improve quality in epithelial ovarian cancer management. J Ovarian Res. 2013; 6:19.

8. Mandato VD, Magnani E, Abrate M, Casali B, Nicoli D, Farnetti E, Formisano D, Pirillo D, Ciarlini G, De Iaco P, Strada I, Zamagni C, La Sala GB. Haptoglobin phenotype and epithelial ovarian cancer. Anticancer Res. 2012:32: 4353-8.

9. de Graeff P, Crijns AP, de Jong S, Boezen M, Post WJ, de Vries EG, van der Zee AG, de Bock GH. Modest effect of p53, EGFR and HER-2/neu on prognosis in epithelial ovarian cancer: a meta-analysis. Br J Cancer. 2009;101: $149-59$.

10. Mandato VD, Torricelli F, Mastrofilippo V, Ciarlini G, Pirillo D, Farnetti E, Fornaciari L, Casali B, Gelli MC, Abrate M, Aguzzoli L, La Sala GB, Nicoli D. Prognostic Impact of ABO Blood Group on Type I Endometrial Cancer Patients- Results from Our Own and Other Studies. J Cancer. 2017;8:2828-35.

11. Aird I, Bentall HH, Roberts JA. A relationship between cancer of stomach and the ABO blood groups. Br. Med. J. 1953;1: 799-801.

12. Rummel SK, Ellsworth RE. The role of the histoblood ABO group in cancer. Future Sci OA. 2016;2:FSO107.

13. Wang Z, Liu L, Ji J et al. ABO blood group system and gastric cancer: a case-control study and meta-analysis. Int. J. Mol. Sci. 2012;13: 13308-13321.

14. Risch HA, Lu L, Wang J et al. ABO blood group and risk of pancreatic cancer: a study in Shanghai and meta-analysis. Am. J. Epidemiol. 2013;177: 1326-1337.

15. Franchini M, Liumbruno GM, Lippi G. The prognostic value of ABO blood group in cancer patients. Blood Transfus. 2016;14: 434-40.

16. Cutrera A, Leoni R. Blood-group incidence (ABO system) in patients with mammary, ovarian and uterine neoplasms. Riv Ostet Ginecol. 1959;14: 737-44

17. Poole EM, Gates MA, High BA, Chanock SJ, Cramer DW, Cunningham JM, Fridley BL, Gayther SA, Goode EL, Iversen ES, Lissowska J, Palmieri Weber RT, Pharoah PD, Phelan CM, Ramus SJ, Schildkraut JM, Sutphen R, Tsai YY, Tyrer J, Vierkant RA, Wentzensen N, Yang HP, Terry KL, Tworoger SS. ABO blood group and risk of epithelial ovarian cancer within the Ovarian Cancer Association Consortium. Cancer Causes Control. 2012;23: 1805-10.

18. Zhou J, Yang LC, He ZY, Li FY, Wu SG, Sun JY. Prognostic Impact of ABO Blood Group on the Survival in Patients with Ovarian Cancer. J Cancer. 2015;6: 970-5.

19. Zhang BL, He N, Huang YB, Song FJ, Chen KX. ABO blood groups and risk of cancer: a systematic review and meta-analysis. Asian Pac J Cancer Prev. 2014;15: 4643-50. 
20. Yuzhalin AE, Kutikhin AG. ABO and Rh blood groups in relation to ovarian, endometrial and cervical cancer risk among the population of South-East Siberia. Asian Pac J Cancer Prev. 2012;13: 5091-6.

21. Gates MA, Wolpin BM, Cramer DW, Hankinson SE, Tworoger SS. ABO blood group and incidence of epithelial ovarian cancer. Int J Cancer. 2011;128: 482-6.

22. Marinaccio M, Traversa A, Carioggia E, Valentino L, Coviello M, Salamanna $\mathrm{S}$, Dragone DC, Marinaccio L. Blood groups of the ABO system and survival rate in gynecologic tumors. Minerva Ginecol. 1995;47: 69-76.

23. Henderson J, Seagroatt V, Goldacre M. Ovarian cancer and ABO blood groups. J Epidemiol Community Health. 1993;47: 287-9.

24. Marinaccio M, Trerotoli C, Battarino O, Maggio F, Damiani L, Carioggia E, Tempesta R, Olivieri M, Salamanna S. Sistema abo e neoplasie ginecologiche. Folia Oncol 1987;10: 138-146.

25. Illeni MT, Pasquali M, La Monica G, Böhm S, Rovini D, Di Re E. HLA antigens in ovarian adenocarcinoma patients. Eur J Gynaecol Oncol. 1985;6: $121-5$

26. Mori M, Kiyosawa H, Miyake H. Case-control study of ovarian cancer in Japan. Cancer. 1984;53: 2746-52.

27. Björkholm E. Blood group distribution in women with ovarian cancer. Int J Epidemiol. 1984:13:15-7.

28. Cozzi M, Gualandri V. On the relations between blood groups of the ABO system and neoplasms of the female genital system. I. Ovarian carcinoma. Minerva Ginecol. 1967;19: 968-72.

29. Osborne RH, Degeorge FV. The ABO blood groups in neoplastic disease of the ovary. Am J Hum Genet. 1963;15: 380-8.

30. Montavon Sartorius C, Schoetzau A, Kettelhack H, Fink D, Hacker NF, Fedier A, Jacob F, Heinzelmann-Schwarz V. ABO blood groups as a prognostic factor for recurrence in ovarian and vulvar cancer. PLoS One. 2018;13:e0195213.

31. Seebacher V, Polterauer S, Reinthaller A, et al. AB0 blood groups and rhesus factor expression as prognostic parameters in patients with epithelial ovarian cancer - a retrospective multi-centre study. BMC Cancer. 2018;18:447.

32. Von Elm E, Altman DG, Egger M. et al. The Strengthening the Reporting of Observational Studies in Epidemiology (STROBE) Statement: guidelines for reporting observational studies. PLoS Med. 2007;4(10):e296 doi: 10.1371/journal.pmed.0040296

33. Reggio Emilia. Linee guida sulla diagnosi e trattamento del carcinoma ovarico. 2011. http://assr.regione.emilia-romagna.it/it/servizi/ pubblicazioni/rapporti-documenti/linee-guida-carcinoma-ovaio

34. Linee guida AIOM Tumori dell'ovaio. 2018

35. Ledermann JA, Raja FA, Fotopoulou C, Gonzalez-Martin A, Colombo N, Sessa C; ESMO Guidelines Working Group. Newly diagnosed and relapsed epithelial ovarian carcinoma: ESMO Clinical Practice Guidelines for diagnosis, treatment and follow-up. Ann Oncol. 2013; 24:24-32.

36. Huang JY, Wang R, Gao YT, Yuan JM. ABO blood type and the risk of cancer - Findings from the Shanghai Cohort Study. PLoS One2017;12:e0184295.

37. Greenwell P. Blood group antigens: molecules seeking a function? Glycoconj. J. 1997;14: 159-173

38. Zhang S, Zhang HS, Cordon-Cardo C, et al. Selection of tumor antigens as targets for immune attack using immunohistochemistry: II. Blood group-related antigens. Int J Cancer 1997; 73: 50-6.

39. Hakomori S. Antigen structure and genetic basis of histo-blood groups A, B and O: their changes associated with human cancer. Biochim Biophys Acta 1999; 1473: 247-66.

40. Hakomori S. Tumor-associated carbohydrate antigens defining tumor malignancy: basis for development of anti-cancer vaccines. Adv Exp Med Biol 2001; 491: 369-402.

41. Melzer D, Perry JR, Hernandez D, et al. A genome-wide association study identifies protein quantitative trait loci (pQTLs). PLoS Genet 2008; 4: e1000072.

42. Pare G, Chasman DI, Kellogg M, et al. Novel association of ABO histo-blood group antigen with soluble ICAM-1: results of a genome-wide association study of 6,578 women. PLoS Genet 2008; 4: e1000118.

43. Devlin J, Elder PA, Gabra $\mathrm{H}$, et al. High frequency of chromosome 9 deletion in ovarian cancer: evidence for three tumour-suppressor loci. Int J Cancer 2004;109:230-7.

44. Yazer $\mathrm{MH}$. What a difference 2 nucleotides make: a short review of $\mathrm{ABO}$ genetics. Transfus Med Rev 2005;19:200-9.

45. Hakomori S. Glycosylation defining cancer malignancy: new wine in an old bottle. Proc Natl Acad Sci U S A 2002;99:10231-3.

46. Gao S, Worm J, Guldberg P, et al. Genetic and epigenetic alterations of the blood group ABO gene in oral squamous cell carcinoma. Br J Cancer 1996;73: 420-3.

47. Kwabi-Addo B, Chung W, Shen L, et al. Age-related DNA methylation changes in normal human prostate tissues. Clin Cancer Res 2007;13: 3796-802.

48. Marsit CJ, Houseman EA, Schned AR, et al. Promoter hypermethylation is associated with current smoking, age, gender and survival in bladder cancer. Carcinogenesis 2007;28: 1745-51. 